\title{
A importância da educação empreendedora para a cultura e formação de novos empreendedores
}

\author{
Luciano de Los Santos Nunes ${ }^{1}$ \\ Mario Fernando Mello ${ }^{2}$
}

\begin{abstract}
Resumo
Transformar uma ideia em negócio num tempo em que ser empreendedor é quase imperativo requer muito mais do que visão de futuro e talento individual. As dificuldades e os desafios para jovens empreendedores fazem parte da realidade em que o mercado apresenta. Por isso, desenvolver os talentos individuais orientados ao empreendedorismo é uma missão com a qual a educação empreendedora pode contribuir. $O$ ensino do empreendedorismo deve ser expandido em escolas e universidades a fim de preparar os jovens para o ambiente de negócios. O jovem empreendedor deve ser um protagonista responsável e assim contribuir com o desenvolvimento da sua região e do seu país. $\mathrm{O}$ presente estudo tem como objetivo principal analisar o referencial teórico estudado e a partir disso propor uma série de características e habilidades que podem se originar da educação empreendedora visando a qualificação e preparação para jovens empreendedores terem sucesso em seus empreendimentos. Como resultado do estudo, apresenta-se um compilado de características, habilidades e desenvolvimento de potencialidades que no contexto empreendedor são necessárias ao jovem empreendedor.
\end{abstract}

Palavras-chave: Educação empreendedora; jovem empreendedor; características empreendedoras; habilidades empreendedoras.

The importance of entrepreneurial education for culture and training of new entrepreneurs

\begin{abstract}
Turning an idea into a business in a time when being an entrepreneur is almost imperative requires much more than foresight and individual talent. The difficulties and challenges for young entrepreneurs are part of the reality in which the market presents. Therefore, developing individual entrepreneurial oriented skills is a mission that entrepreneurship education can contribute. The teaching of entrepreneurship should be expanded in schools and universities to prepare young people for the business environment. The young entrepreneur must be a responsible protagonist and thus contribute to the development of his region and his country. The main objective of this study is to analyze the theoretical framework studied and, from this, propose a series of characteristics and abilities that can originate from the entrepreneurial education aiming the qualification and preparation for young entrepreneurs to succeed in their ventures. As a result of the study it presents a compilation of characteristics, abilities and development of potentialities that in the entrepreneurial context are necessary to the young entrepreneur.
\end{abstract}

Key-words: Entrepreneurial education; young entrepreneur; features; skills.

La importancia de la educación emprendedora para la cultura y formación de nuevos emprendedores

\section{Resumen}

Transformar una idea en negocio en un tiempo en que ser emprendedor es casi imperativo requiere mucho más que visión de futuro y talento individual. Las dificultades y los

\footnotetext{
${ }^{1}$ Acadêmico do $8^{\circ}$ semestre do Curso de Administração da Universidade Luterana do Brasil, ULBRA.

${ }^{2}$ Professor Universitário de Graduação e Pós-Graduação nos cursos de Administração, Arquitetura, Engenharia de Produção e Engenharia Química. Graduado em Engenharia Op.Mecânica e Ciências Contábeis e Mestre em Engenharia de Produção. Possui MBA em Formação de Gerentes. Doutorando em Engenharia. É Professor na Faculdade Antonio Meneghetti, AMF.
} 
desafíos para los jóvenes emprendedores forman parte de la realidad en que el mercado presenta. Por eso, desarrollar los talentos individuales orientados al espíritu emprendedor es una misión que la educación emprendedora puede contribuir. La enseñanza del espíritu empresarial debe ampliarse en las escuelas y las universidades para preparar a los jóvenes en el entorno empresarial. El joven emprendedor debe ser un protagonista responsable y así contribuir con el desarrollo de su región y de su país. El presente estudio tiene como objetivo principal analizar el referencial teórico estudiado y, a partir de ello, proponer una serie de características y habilidades que pueden originarse de la educación emprendedora visando la cualificación y preparación para que jóvenes emprendedores tengan éxito en sus emprendimientos. Como resultado del estudio, se presenta un compilado de características, habilidades y desarrollo de potencialidades que en el contexto emprendedor son necesarias al joven emprendedor.

Palabras clave: Educación emprendedora; joven emprendedor; características; habilidades.

\section{Introdução}

Empreender e criar um novo negócio tem um papel social muito relevante para o desenvolvimento de uma empresa, cidade ou até mesmo do país. A cultura empreendedora representa a essência do empreendedorismo. Significa ter o perfil empreendedor, gestão empreendedora e também atitudes proativas em relação a empreender. O comportamento empreendedor e da cultura empreendedora são componentes essenciais para a sobrevivência e o sucesso das organizações num mercado com tanta competição, com mudanças tão rápidas e constantes (DREHER, 2004).

Para ser empreendedor é preciso superar muitos desafios, pois transformar o sonho em realidade, ou seja, transformar projetos em ações concretas é um caminho difícil e requer preparo com uma formação continuada sob a perspectiva da psicologia do líder. Por trás das novas ideias inerentes ao empreendedorismo é necessário que haja análise, planejamento estratégico-operacional, capacidade de implementação dessas novas ideias e principalmente uma formação liderística interdisciplinar sólida.

O jovem deve aprender a saber como construir a si mesmo como pessoa e como líder. Neste contexto surge a educação empreendedora para contribuir com o protagonismo responsável do jovem empreendedor. Na visão de Meneghetti (2017) é preciso encontrar, selecionar o que é útil e funcional, pois é indispensável saber fazer esta conjugação constante.

Assim, o objetivo principal deste estudo é fazer uma análise do referencial teórico que o embasa para propor uma série de características e habilidades que podem se originar da educação empreendedora visando a qualificação e preparação para jovens empreendedores terem sucesso em seus empreendimentos. 


\section{Referencial Teórico}

Neste capítulo serão abordados os principais temas relacionados ao presente estudo e que irão embasar teoricamente a pesquisa.

\subsection{Educação Empreendedora}

O empreendedorismo, segundo Dornelas (2016), envolve o processo de criação de algo novo, de algo com valor para a sociedade. Requer a devoção, o comprometimento de tempo e o esforço necessário para o negócio crescer, além da ousadia em assumir riscos e de

tomar decisões críticas ao longo do tempo. Por isso a importância da educação empreendedora se acentua na medida em que o jovem deve tornar-se protagonista da sua evolução e do seu desenvolvimento humano.

Dolabela (2008) entende que o empreendedorismo deve ter importância para a sociedade, ou seja, um dos fundamentos do empreendedorismo é o bem-estar coletivo e o espírito comunitário. Kawasaki (2016), destaca que quando se fala em dar sentido à sua empresa, não significa apenas convertê-la em uma máquina de fazer dinheiro, prestígio ou poder.

Criar sentido significa ajudar a converter o mundo em um lugar melhor, através da contribuição que você como líder e sua empresa podem dar. Neste sentido o jovem empreendedor deve operar com as duas morais. "O Eu deve aprender a conjugar essa dupla moral: a moral profunda da vida em si mesmo, para si mesmo defronte da vida e a moral de um indivíduo cívico em relação aos outros, que observam as mesmas leis, os mesmos deveres que ela vive" (MENEGHETTI, 2014, p. 197).

Assim, num contexto cheio de desafios é que se apresenta a educação empreendedora, para suprir o déficit de conhecimento e competências que o jovem empreendedor possui na busca de autonomia e de técnicas para a solução de problemas.

Dolabela (2008) afirma que a educação empreendedora no Brasil está em seu estágio inicial de desenvolvimento. Segundo ele, "a educação empreendedora no Brasil difere daquela nos países desenvolvidos: aqui as variáveis que definem a nossa ética e a nossa estratégia educacional advêm de contingências não encontradas lá: a miséria e os mecanismos históricos de sua preservação".

O empreendedorismo deve ser envolvido por pessoas e por processos que, em conjunto, fazem a sintetização de ideias em possíveis oportunidades, voltado para o foco 
principal do empreendedorismo, que é justamente gerar oportunidades (DORNELAS, 2008). Ainda, segundo Dolabela (2008), é necessário refletir sobre os valores do ensino no Brasil, visando difundir a cultura empreendedora como um fator gerador de oportunidades e como promotor do desenvolvimento.

Empreendedores que possuem habilidades e atuam em conjunto, colocando suas competências em prática, conseguem adaptar-se a situações novas e complexas, podendo enfrentar desafios e iniciar transformações, assim propícios a ocupar um papel principal na sociedade. Greatti (2005) acredita que por trás do sucesso de uma empresa há, certamente, uma boa ideia e alguém com talento e disposição suficientes para transformá-la em realidade.

Além de todas as características que lhe são atribuídas, o empreendedor é aquele capaz de identificar boas oportunidades, assumir riscos, enfrentar adversidades e, principalmente, conduzir seu negócio ao sucesso. Diante desse contexto, a educação empreendedora passou a ter um destaque estratégico no campo econômico e social no cenário brasileiro empreendedor (SEBRAE, 2017).

\subsection{O ensino como agente formador de uma cultura empreendedora}

A cultura empreendedora baseia-se na concentração de várias formas de empreendedorismo, necessárias para a determinação desta cultura. No entendimento de Dreher (2004), existem várias iniciativas ou formas de empreendedorismo, como o perfil empreendedor, a gestão empreendedora, o intraempreendedorismo, o empreendedorismo coletivo; segundo esse autor, para existir cultura empreendedora são necessárias ao menos duas dessas formas. A cultura empreendedora enfatiza a emergência de novas oportunidades, os meios de capitalizá-las e a criação de estrutura adequada para aproveitá-las.

O início do ensino de empreendedorismo nas Instituições de Ensino Superior - IES está associado ao curso de administração de empresas (LAVIERI, 2010). Carvalho e Zuanazzi (2003, p. 7) observam que a disciplina de empreendedorismo tem sido aplicada prioritariamente no ensino superior, conquanto "[...] é crítico que as instituições de ensino definam quais são os objetivos da disciplina e para quem está sendo ministrada, pois, conhecer o seu aluno e saber quais são as suas expectativas, são requisitos necessários para a efetividade do ensino".

Segundo Oliveira (2003), a experiência em disciplinas sobre empreendedorismo fornece evidências de que é possível despertar o espírito empreendedor nos alunos. A estratégia e o planejamento são os alicerces da cultura empreendedora, para diminuir as 
incertezas nas oportunidades de negócios, o que está em conformidade com a atitude do empreendedor de sempre calcular o risco de maneira premeditada (STEVENSON e GUMPERT, 1985).

É necessário formar empreendedores e a universidade tem um papel essencial, pois as Instituições de Ensino Superior (IES) podem criar um programa de formação empreendedora com disciplinas eletivas e/ou obrigatórias, cursos sequenciais, seminários e oficinas (OLIVEIRA, 2006).

Assim, a inclusão do ensino do empreendedorismo nos cursos de graduação superior deve assumir um caráter de dupla dimensão. Suas bases e fundamentos devem ser adequadamente estudados, para que seja definida uma metodologia abrangente que venha envolver aspectos técnicos e atitudinais. Tal metodologia deve mostrar para o aluno de graduação a importância de desenvolver o empreendedorismo para si e para o desenvolvimento de outros empreendedores, e o quanto essa mudança de mentalidade deve resultar em seu amadurecimento pessoal como profissional e no desenvolvimento da sociedade onde atua.

A educação empreendedora surge como importante mecanismo que uma nação possui para se obter o desenvolvimento e reconhecimento tanto nacional quanto mundial, e tem sido colocada como prioritária nas agendas e debates políticos, econômicos e acadêmicos, incluindo os mais altos níveis de discussão das Nações Unidas (UNCTAD, 2015; LIMA et. al., 2015a).

Lopes e Teixeira (2010) afirmam que uma formação empreendedora enfatiza o uso intenso de metodologias de ensino que permitem aprender fazendo, e se caracteriza por isso, pois o indivíduo se defronta com eventos críticos que o forçam a pensar de maneira diferente, buscando saídas e alternativas, ou seja, aprendendo com a experiência, com o processo.

Segundo Guerra e Grazziotin (2010), os desafios que o empreendedorismo impõe à educação formal nas Instituições de Ensino Superior - IES convergem, para um único ponto: o desafio da superação.

De acordo com Lopes e Teixeira (2010, p. 26):

O conceito de Educação Empreendedora abrange todos os níveis educacionais, incluindo tanto a concepção mais ampla segundo a qual o ensino promove o desenvolvimento de atitudes e habilidades que não são diretamente relacionadas à criação de novos negócios, quanto uma concepção mais restrita e que focaliza a criação de um negócio. 
Na visão de Guerra e Grazziotin (2010), o assunto empreendedorismo deve ser tratado em todos os cursos e em todos os níveis. A dinâmica ambiental em que as organizações estão inseridas não permite mais que os empreendedores administrem da mesma forma que faziam no passado.

Novaes e Gil (2009, p. 151) advertem que "as múltiplas manifestações de empreendedorismo indicam a necessidade de novas abordagens acerca do fenômeno empreendedor, que possibilitem o entendimento do processo empreendedor com base na experiência de vida e nas representações das pessoas".

Dornelas (2016) questiona se é possível ensinar empreendedorismo, pois até alguns anos atrás se acreditava que o empreendedor era inato, ou seja, que nascia com um dom diferenciado e era predestinado ao sucesso nos negócios.

Essa concepção mudou e a cada dia que passa acredita-se, segundo Dornelas (2016), que o processo empreendedor pode ser ensinado e entendido por qualquer indivíduo e que o sucesso pode decorrer de vários fatores. Entre eles destacam-se:
a) Fatores internos ao negócio;
b) Fatores externos ao negócio;
c) Perfil do empreendedor;
d) Como ele administra as adversidades do dia-a-dia;
e) Quais técnicas são utilizadas para gerir o negócio;
f) Qual o mercado que o negócio está inserido.

Ainda segundo Dornelas (2016) os empreendedores inatos continuam existindo e muitas vezes podem ser referência aos mais novos, porém a capacitação para novos empreendimentos pode aliar a intuição para o negócio com o aprendizado de técnicas para o empreendedorismo. O mesmo autor destaca que, com certeza, a junção do dom com o ensino de empreendedorismo ajudará na formação de melhores empresários, melhores empresas e na maior geração de riqueza ao país.

Saini (2001) destaca que o empreendedorismo desempenha importante papel na redução da pobreza, porém as classes mais baixas carecem de educação para enfrentar as barreiras que são significativas no processo de empreender. No contexto brasileiro os níveis de desigualdade social ainda são elevados e as classes mais desfavorecidas têm mais dificuldades na educação. Ressalta ainda o mesmo autor que o crescimento da classe média alta por via do empreendedorismo e vice-versa aumentaria a prosperidade e reduziria as diferenças entre as classes. 
Para Audrestsch, Bont, Tamvada (2013), as barreiras de recursos para empreender, junto com fatores que limitam o desenvolvimento de uma cultura empreendedora, têm, por consequência, uma menor incidência do comportamento empreendedor. As constatações desses autores sugerem que a educação empreendedora ajudaria a romper com muitas barreiras, gerando conhecimento útil para empreendedores.

Para que se tenha uma nação de reconhecido valor e excelência, não só no Brasil, mas em âmbito mundial, é de vital importância a educação e a cultura empreendedora nas organizações. Hoje, diante da diversificação e complexidade da sociedade contemporânea, [o contexto sócio histórico] obriga que a metodologia de educação instigue novas atitudes e habilidades para os futuros empreendedores.

\subsection{Cultura Empreendedora}

A cultura empreendedora é fundamental, pois representa a essência do empreendedorismo, e pode manifestar-se de várias formas. É o cenário para o fomento da inovação, da busca, seleção e identificação de oportunidades, do trabalho criativo e do trabalho mais integrado. Para Drucker (2016), o comportamento empreendedor está vinculado ao cultural, ao psicológico, bem como ao tecnológico.

As causas desse comportamento possivelmente estão nas mudanças de valores, de percepções, de atitudes, bem como nas mudanças nas instituições sociais e na educação. Conforme Zhao (2005), a cultura empreendedora possui uma influência profunda no nível de empreendedorismo das organizações, uma vez que esta é um fator determinante de empreendedorismo e inovação.

Rezende (2014) afirma que conforme as estimativas da Endeavor Brasil, organização de fomento da cultura empreendedora, apenas $9 \%$ da população adulta brasileira passa pela educação empreendedora, índice considerado muito baixo se comparado com outros países da América Latina, como o Chile, por exemplo, que tem taxas de $40 \%$.

A manutenção de uma cultura empreendedora ao longo dos anos compreende certos fatores, tais como: a criação de valor; o foco nas pessoas; o gerenciamento com ênfase prática, sem excesso de formalismo; a eficácia, que se aprimora com a experiência e com a gestão do conhecimento; o comprometimento com a organização, a responsabilidade, a ética e a ênfase no futuro; e a liberdade para fazer a organização crescer, mesmo estando sujeito a falhas (DORNELAS, 2008). 
Greatti e Previdelli (2003) sugerem que, embora as características empreendedoras possam ser desenvolvidas ou adquiridas, o principal elemento que influencia a formação do perfil empreendedor é o ambiente cultural no qual está inserido. Quando se aborda o empreendedorismo, defronta-se com o senso comum da maioria das pessoas, que considera que as características empreendedoras do ser humano são inatas e, portanto, apenas uma minoria eleita nasceria com esse dom, enquanto a maioria estaria destinada a exercer sua atividade econômica na condição de assalariado (DOLABELA, 2000).

\subsection{Principais modelos de dimensões culturais}

As características culturais de uma determinada região podem ser analisadas por meio de sua diversidade de dimensões culturais, que tentam explicar diversos traços e comportamentos da população que lá habita. Dentre os vários modelos de dimensões culturais existentes, quatro dos mais aceitos, difundidos e citados são os de Hofstede, de Trompenaars e Hampden-Turner, de Hall e de Schwartz.

Na visão de Lacerda (2011), Dias (2012), Nardon e Steers (2009) e Schwartz (2012), o modelo das dimensões culturais de Geert Hofstede é um quadro-referência que descreve cinco tipos (dimensões) de diferenças/perspectivas de valores entre as culturas nacionais; já o de Trompenaars e Hampden-Turner baseia-se no conceito de que cada cultura tem as suas especificidades previsíveis que podemos usar para "categorizar" os recursos. O modelo de Hall analisa a comunicação interpessoal, o uso do espaço, a percepção do tempo e a velocidade com que mensagens são transmitidas em uma sociedade, enquanto o modelo de Schwartz tem ênfase nos valores humanos universais presentes em qualquer cultura, tais valores representam as necessidades universais da existência humana.

No Quadro 1 estão demonstradas as principais dimensões culturais no Brasil. 
Quadro 1 - Principais dimensões culturais

\begin{tabular}{|c|c|c|}
\hline \multirow{6}{*}{ 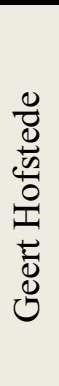 } & Dimensão & Escala \\
\hline & Distância do Poder & alta \\
\hline & Resistência à Incerteza & alta \\
\hline & Individualismo e Coletivismo & coletivista \\
\hline & Masculinidade e Feminilidade & intermediária \\
\hline & Dinamismo Confuciano & orientação ao longo prazo \\
\hline \multirow{8}{*}{ 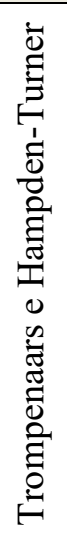 } & Dimensão & Escala \\
\hline & Universalismo/Particularismo & particularista \\
\hline & Individualismo Coletivismo & coletivista \\
\hline & Específico/Difuso & difuso \\
\hline & Neutro/Afetivo & afetivo \\
\hline & Relização/Atribuição & atribuição \\
\hline & Perspectivva de tempo & orientação ao futuro \\
\hline & Relacionamento com o ambiente & direcionamento externo \\
\hline \multirow{4}{*}{$\overline{\bar{\Xi}}$} & Dimensão & Escala \\
\hline & Contexto & alto contexto \\
\hline & Espaço & comunal \\
\hline & Tempo & policromático \\
\hline \multirow{4}{*}{ 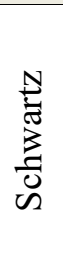 } & Dimensão & Escala \\
\hline & Conservadorismo/Autonomia & conservadorismo \\
\hline & Hierarquia/Igualitarismo & hierarquia \\
\hline & Domínio/Harmonia & harmonia \\
\hline
\end{tabular}

Fonte: Adaptado de Lacerda (2011), Dias (2012), Nardon e Steers (2009), Schwartz (2012).

Ritchie e Brindley (2005)bb defendem que a cultura empreendedora é influenciada por quatro fatores determinantes:

- O contexto macro empreendedor, que depende das políticas, procedimentos e infraestruturas, que podem facilitar ou inibir o empreendedorismo, como as políticas de governo e mecanismos de apoio a pequenos negócios locais.

- O contexto do indivíduo empreendedor, que está ligado a fatores que influenciarão diretamente cada indivíduo em seu desenvolvimento.

- O terceiro elemento que influencia o indivíduo no desenvolvimento de uma carreira empreendedora são as suas características pessoais, que podem incluir: 
atitudes para auto emprego, atitude de correr riscos, idade, autoconfiança, nível educacional e gênero.

- Os processos e práticas empresariais que sugerem que pode haver diferenças na maneira pela qual a atividade empresarial é iniciada, desenvolvida e sustentada.

\subsection{Objetivos da Educação Empreendedora}

A educação, segundo Bolson (2008), é o único caminho para criar uma sociedade mais empreendedora no Brasil. O processo é lento. O potencial empreendedor é enorme, mas está latente. É hora de criar novos motores para os negócios. É tempo de despertar os jovens para uma nova maneira de viver. É hora de formar uma nova geração de brasileiros. É tempo de disseminar a educação empreendedora, desde o ensino fundamental até o superior.

A importância da educação empreendedora para o desenvolvimento de uma nação tem sido reconhecida, não apenas no Brasil, mas em diversos países do mundo, tendo sido colocada como prioritária nas agendas e debates políticos, econômicos e acadêmicos, incluindo os mais altos níveis de discussão das Nações Unidas (UNCTAD, 2015).

Para Dornelas (2016) entender quais são os objetivos da educação empreendedora é fundamental pois existem diferenças entre universidades ou escolas técnicas. Assim, qualquer curso sobre empreendedorismo, deveria focar em:

a) Identificação e entendimento das habilidades do empreendedor;

b) Como ocorre a inovação e o processo empreendedor;

c) De como ocorre a importância do empreendedorismo para o desenvolvimento econômico;

d) Em como preparar e utilizar um Plano de Negócios;

e) Em como identificar fontes de financiamento para o novo negócio;

f) Em como identificar a obtenção de financiamento para o novo negócio;

g) Como gerenciar a empresa;

h) Como fazer a empresa crescer.

Destaca Dornelas (2016) que são requeridas habilidades de um empreendedor, que também podem ser adquiridas pela educação empreendedora. Essas habilidades podem ser divididas em três áreas: técnicas, gerenciais e características pessoais. Assim, enfatiza Dornelas (2016), a decisão de tornar-se empreendedor pode ser valorizando suas capacidades e habilidades inatas e buscando a complementação com a educação empreendedora. 
Ainda segundo o mesmo autor, alguns fatores influenciam mais o processo de empreender. A Figura 1 demonstra esses fatores e mostra o que influencia o processo empreendedor. Importante destacar que o talento empreendedor resulta da percepção, direção e dedicação dos empreendedores.

Figura 1 - Fatores que influenciam o processo empreendedor.

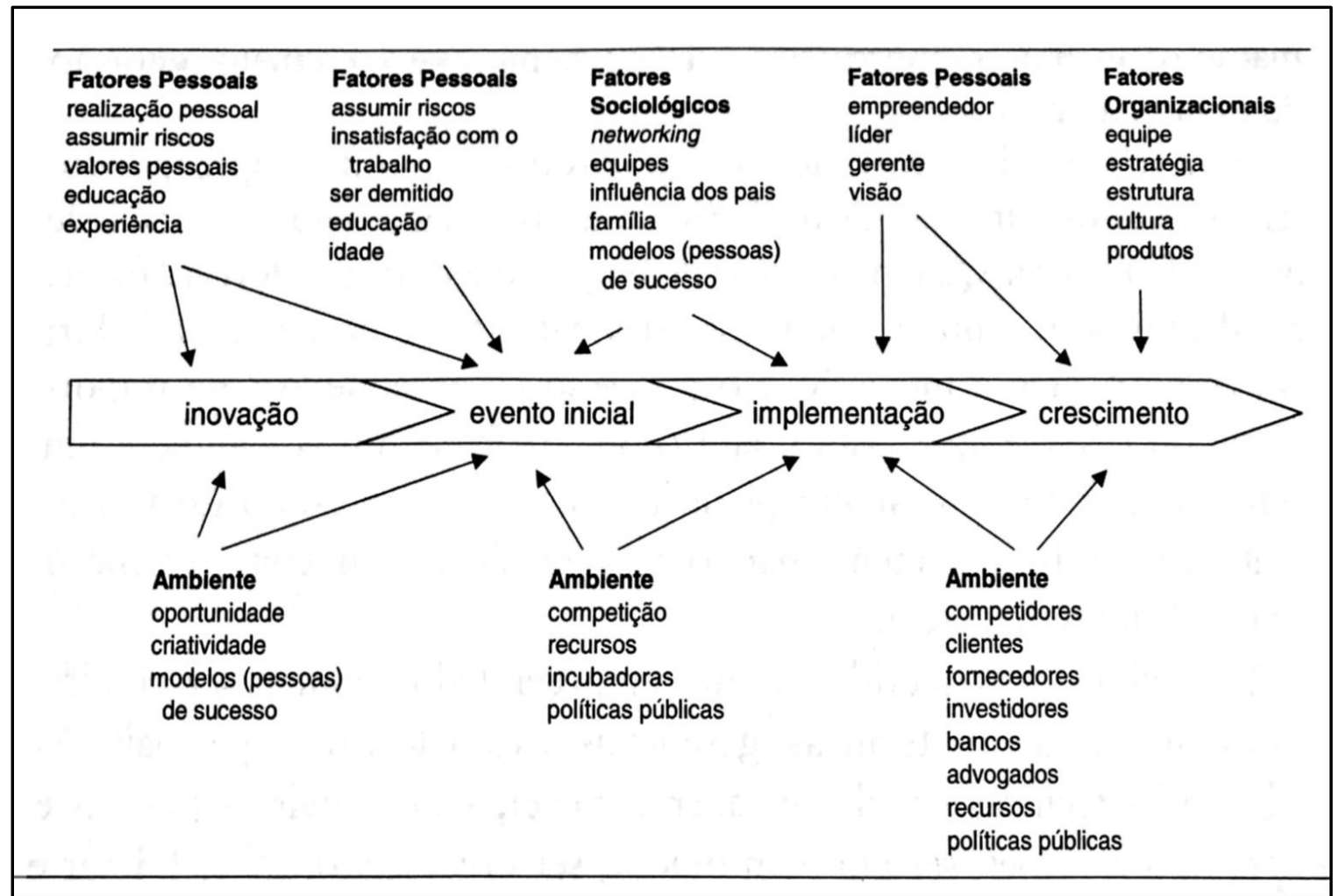

Fonte: Dornellas, 2016

Para Dornelas (2016), o talento sem ideias é como uma semente sem água, ou seja, quando o talento empreendedor é somado às técnicas de empreender, as chances de sucesso aumentam muito. A figura 2 apresenta essas habilidades.

Figura 2 - Fatores críticos para o sucesso econômico

1. Talento - Pessoas

2. Tecnologia - Ideias

3. Capital - Recursos

Negócios de

4. Know-how-Conhecimento 
Assim, na visão de Dornelas (2016), convergir em um mesmo ambiente o talento, a tecnologia e o capital fazem a empresa crescer e atingir o sucesso e que, portanto, a educação empreendedora contribui muito para a convergência desses fatores. Dolabela (2008) aponta algumas razões e objetivos para se disseminar a cultura empreendedora nas escolas e universidades:

a) Autorrealização: pesquisas indicam que o empreendedorismo oferece elevados graus de realização pessoal, aliando trabalho e prazer;

b) Favorece a formação de líderes: mesmo que as condições ambientais sejam favoráveis à abertura de novos negócios, será através de sua liderança, capacidade e perfil que irá se disparar o processo de desenvolvimento;

c) Apoia a formação de micro e pequenas empresas: através da reorientação dos estudos também para essas em detrimento das grandes empresas. Sabe-se que, ao focar tais estudos, a escola se aproxima da realidade de muitos dos alunos, influenciando-os;

d) Amplia a base tecnológica: as empresas de base tecnológicas surgiram no final da década de 20 como uma das principais forças econômicas;

e) Pesquisadores, professores e alunos de universidades possuem potencial para criação de empreendimentos baseados no conhecimento;

f) Resposta ao desemprego: demonstrando aos alunos que além dos grandes empregos (a maioria em declínio nas grandes corporações), existe a oportunidade da abertura de novos negócios.

\subsection{A importância do uso de técnicas para empreender}

Segundo Kawasaki (2016), empreender é uma arte, porém não se deve abrir mão de técnicas para se chegar mais próximo do sucesso. Muitos empreendedores ficam tão apaixonados pelo seu negócio que muitas vezes não conseguem entender as limitações e acreditam que sempre terão a melhor solução para os problemas da empresa.

Dornelas (2016) ressalta que o bom empreendedor deve reconhecer suas limitações e montar uma equipe de gestão que leve a empresa a se manter competitiva no mercado. Por isso a importância das técnicas para empreender. O mesmo autor destaca que existem quatro grandes áreas de preparação técnica para tornar a ideia do empreendedor em ideia tecnicamente viável. 
a) Análises e providências prévias;

b) Arquitetura e estrutura;

c) Formação de preços, vendas, volume e crescimento;

d) Plano de Negócios.

Por isso, diante da complexidade de empreender, esses elementos são imprescindíveis para o empreendedor aumentar suas chances de sucesso no empreendimento.

Segundo Borges (2014), é necessário que o empreendedor tenha ciência da necessidade e da importância da educação empreendedora. São vários os fatores que influenciam a aprendizagem empreendedora; alguns estão relacionados aos contatos com a dinâmica do contexto externo, outros pelo exercício da auto percepção. O empreendedor neste cenário busca aprimoramento contínuo de suas habilidades, tanto práticas como teóricas, o que acarreta em um fortalecimento de seu potencial competitivo.

\subsection{Estudo das oportunidades}

Identificar uma oportunidade é o primeiro passo para uma pessoa que quer se tornar um empreendedor. Para tanto, ela tem que saber diferenciar oportunidade de ideia. Cada vez mais, as grandes empresas estão buscando soluções para desenvolver e estimular entre seus colaboradores a capacidade empreendedora, além de uma postura voltada à inovação. Assim conseguem suprir a deficiência da formação escolar básica e superior, conscientes de que inovar é função toda a organização.

Segundo Fillion (1999), uma das características marcantes do empreendedorismo é a capacidade de identificar oportunidades, voltada diretamente ao conhecimento que o empreendedor possui dentro do ambiente em que convive. Outrossim, além de reconhecer as oportunidades que possam surgir, deve-se estar sempre atento às novas mudanças que ocorrem em um ambiente e saber agir conforme elas acontecem.

Baron e Shane (2013) defendem que empreendedores devem colocar em prática seus conhecimentos para se reconhecer uma oportunidade. Essa aplicação de conhecimentos incide na habilidade de dar uma percepção e uma projeção de um ambiente aceitável, analisando fatores políticos, sociais e ambientais que devem gerar informação útil para que uma oportunidade seja reconhecida, combinando esses elementos que são fatores chave para o empreendedor inovador. 


\subsection{Ambiente para Empreender no Brasil}

Segundo Sebrae (2017), em 2016 as proporções de brasileiros com percepções positivas sobre a atividade empreendedora se mantiveram em alta. Ocorreu também a diminuição no número de pessoas que sonham ter o próprio negócio ou que enxergam boas oportunidades de negócios no ambiente em que vivem.

Figura 3 - O processo empreendedor segundo GEM 2016

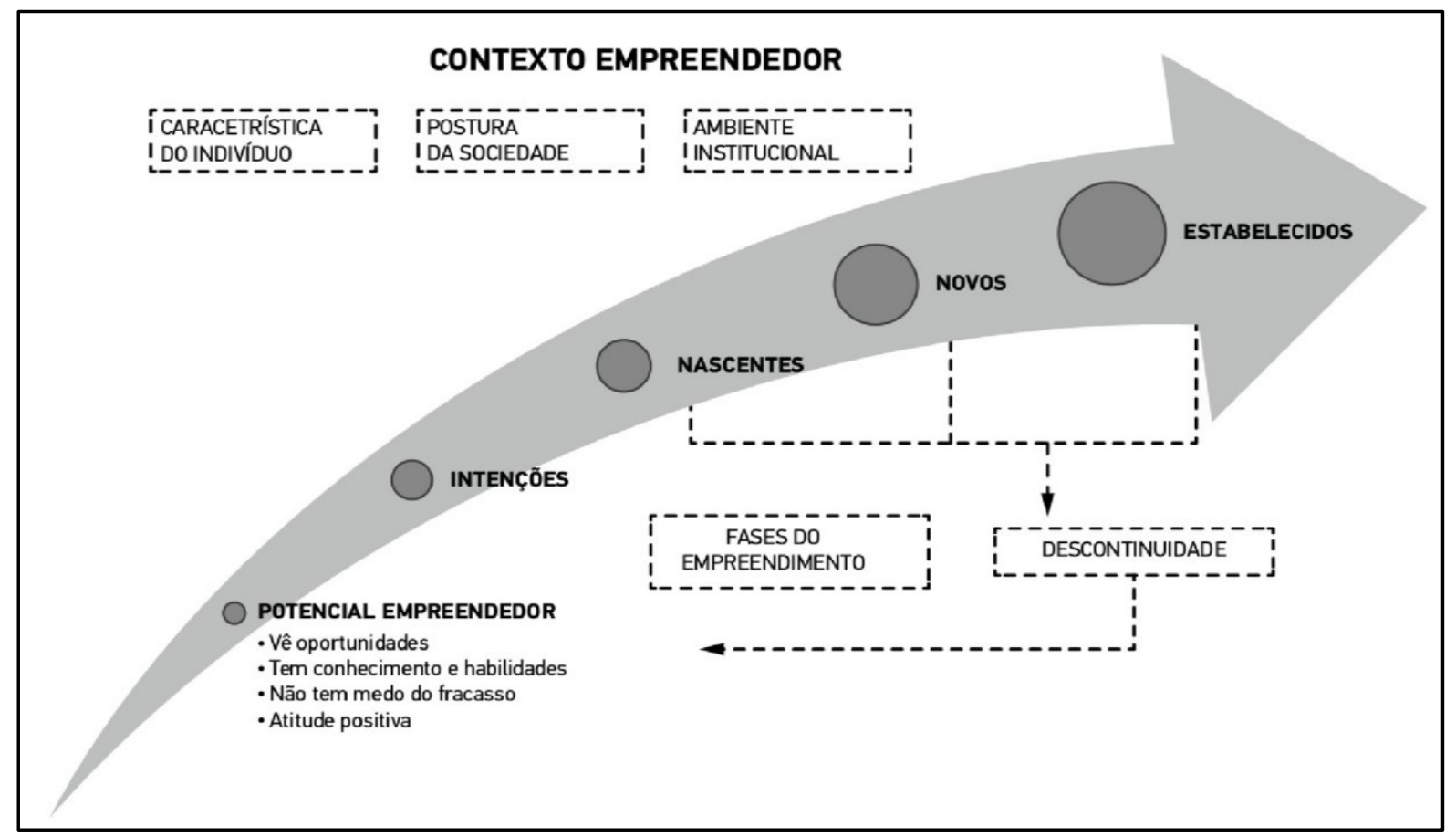

Fonte: GEM 2016.

A motivação dos empreendedores iniciais pode ocorrer pela necessidade ou oportunidade. No Brasil, o ano de 2016 apresentou uma melhora sutil se comparado a 2015 (56,5\%), com o valor de 57,4\%. Portanto, a cada 100 empreendedores, 57 empreendem por oportunidade (SEBRAE, 2017). 
Gráfico 1 - Taxas de empreendedorismo

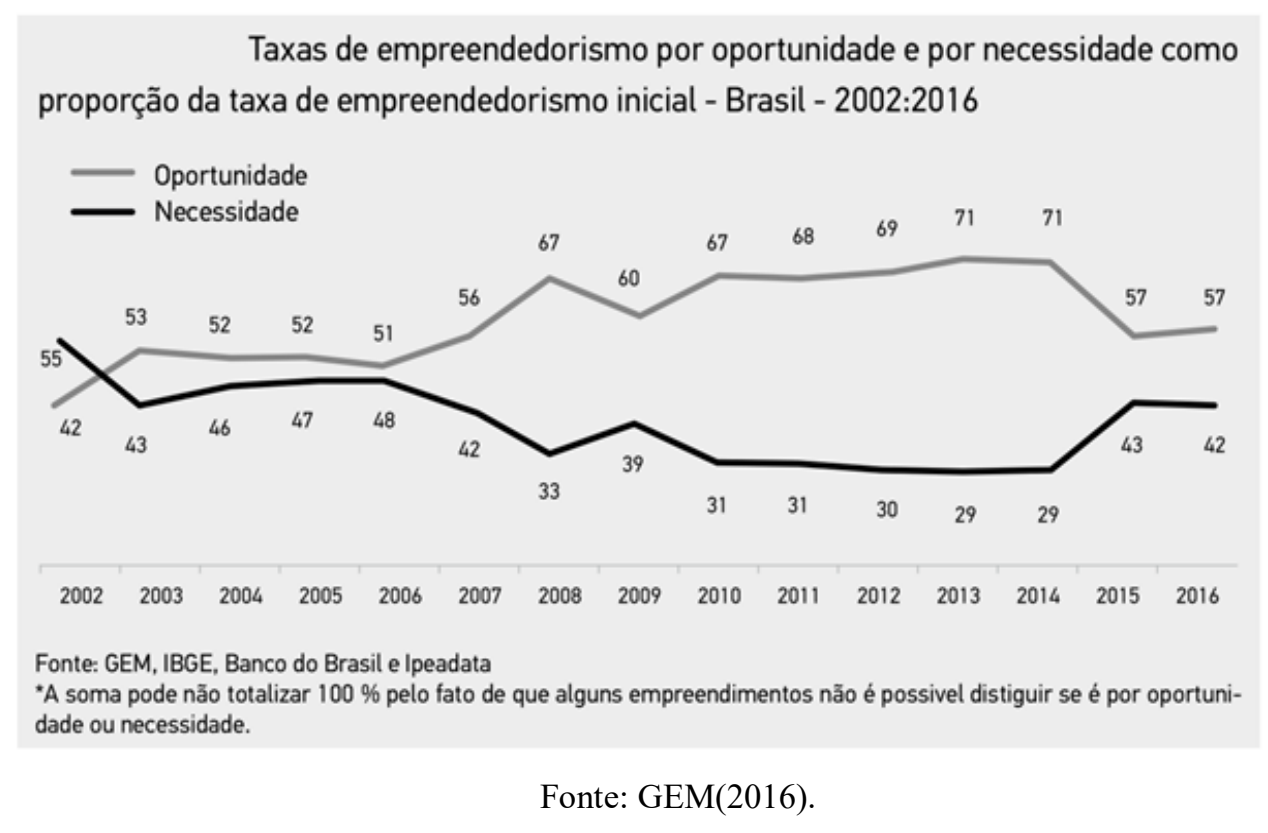

\section{Metodologia}

Quanto aos objetivos, este estudo se trata de uma pesquisa exploratória, que segundo Gil (2008) proporciona maior familiaridade com o problema. Quanto ao procedimento, tem caráter de pesquisa bibliográfica, pois foi desenvolvida com material já elaborado por autores consagrados na temática.

Dessa forma, cabe ao pesquisador estabelecer uma estratégia de pesquisa bibliográfica que tanto facilite a identificação dos principais trabalhos em meio a uma quantidade grande de possibilidades que permeiam a produção científica mundial, como garanta a capacidade de estabelecer as fronteiras do conhecimento advindo dos achados científicos.

A pesquisa foi planejada com flexibilidade, permitindo o estudo do tema sob diversos ângulos e aspectos, envolvendo levantamentos bibliográficos, citações e exemplos que facilitaram o entendimento do assunto.

Pode-se também considerar como uma pesquisa documental, visto que, segundo Gil (2008), os documentos consultados podem ter um tratamento analítico, visando-se um maior entendimento do tema proposto.

A pesquisa foi realizada de junho a novembro de 2018 e traz em seus resultados um compilado de características e habilidades que a educação empreendedora pode desenvolver nos indivíduos empreendedores. 


\section{Resultados}

A partir de uma livre análise dos conceitos e práticas pesquisadas neste estudo, foram identificadas e descritas algumas características recomendáveis para guiar a educação empreendedora no quesito qualificação e capacitação do jovem empreendedor através da educação empreendedora, bem como algumas características necessárias ao empreendedor.

No Quadro 2, baseado em Dornelas (2016), Dolabela (2008) e Drucker (2017), são descritas as habilidades de um empreendedor. Para tornar-se um empreendedor é necessário valorizar estas habilidades que podem ser potencializadas através da educação empreendedora.

Na visão de Meneghetti (2014) é natural que no jovem exista a distância entre o potencial de fazer e o conhecimento do ofício, porque não basta a força, é preciso também a técnica, a experiência e o saber fazer. Por isso, a educação empreendedora aumenta sua importância.

Quadro 2 - Habilidades requeridas de um empreendedor

\begin{tabular}{|l|l|}
\hline Área & Habilidades \\
\hline \multirow{5}{*}{ Técnica } & Saber escrever; \\
& Saber ouvir as pessoas; \\
& Saber captar informações; \\
& Ser um bom orador; \\
& Ser organizado; \\
& Saber liderar; \\
& Saber trabalhar em equipe; \\
& Possuir know-how técnico em sua área de atuação. \\
\hline \multirow{5}{*}{ Gerencial } & Ter conhecimento na criação, desenvolvimento e gerenciamento \\
& de uma nova empresa; \\
& Ter conhecimento em marketing; \\
& Ter conhecimento em finanças; \\
& Ter conhecimento operacional e da produção; \\
& Ter conhecimento em técnicas de tomada de decisões; \\
& Ter conhecimento em técnicas de negociação; \\
& Ter controle sobre as ações da empresa. \\
\hline \multirow{5}{*}{ Características Pessoais } & Ser disciplinado; \\
& Ter discernimento em assumir riscos; \\
& Ser inovador; \\
& Ser orientado a mudanças; \\
& Ser persistente; \\
& Ser um líder visionário. \\
\hline
\end{tabular}


Neste contexto, ampliando o quadro das características pessoais, corroborou-se com Meneghetti (2016) que, em sua visão, na condução de uma obra, o protagonista é a pessoa de destaque, o agente principal, responsável por projetar as inúmeras funções de trabalho para o sucesso e o êxito de todos. Assim, foram criadas dez características pessoais necessárias ao empreendedor.

Quadro 3 - Características pessoais de um empreendedor

\begin{tabular}{|l|l|}
\hline \multicolumn{1}{|c|}{ Característica } & \multicolumn{1}{c|}{ Descrição } \\
\hline Capacidade de sonhar. & O poder das ideias. \\
\hline Intuição e visão de futuro. & Razão e emoção devem andar juntos. \\
\hline Detectar oportunidades. & O sucesso pode estar logo ali. \\
\hline Ter iniciativa. & Não deixar nada para depois. \\
\hline Coragem e ousadia. & Ter discernimento e coragem para enfrentar riscos. \\
\hline Objetivos bem definidos. & Os desvios do caminho traçado devem ser minimizados. \\
\hline Paixão pelo negócio. & Acreditar com paixão no que faz traz resultados. \\
\hline Ter persistência. & Erros acontecerão ao longo da caminhada. Aprenda com eles. \\
\hline Habilidade comercial. & Ter as sutilezas na arte de vender. \\
\hline Liderança & Saber garantir por meio da inteligência a função a todos. Fazer \\
& acontecer. \\
\hline
\end{tabular}

Fonte: Elaborado pelos autores, 2018.

Em relação à Educação Empreendedora, fazendo análise do referencial teórico estudado, pode-se concluir que a mesma precisa fomentar e desenvolver no indivíduo empreendedor suas potencialidades relativas à formação. São apresentadas a seguir dez potencialidades a serem desenvolvidas.

1. Iniciativa: a busca constante por oportunidades de negócios. Estar sempre atento ao que acontece no mercado em que vai atuar.

2. Perseverança: as dificuldades vão acontecer, até porque o empresário de micro e pequena empresa muitas vezes é solitário.

3. Coragem para correr riscos: arriscar-se faz parte do ato de empreender. Diniz ressalta que correr riscos é diferente de correr perigo. O empreendedor corre perigo quando está desinformado. Se tem as informações, pode tomar decisões complexas com risco calculado.

4. Capacidade de planejamento: ter a visão de onde está, onde quer chegar e o que é preciso fazer. Criar planos de ações e priorizá-las dentro do negócio. Monitorar, 
corrigir e rever. Isso pressupõe que se avalie as melhores alternativas para alcançar seus objetivos estabelecidos durante o planejamento.

5. Eficiência e qualidade: as pequenas empresas dispõem de menos recursos, então precisam garantir que eles sejam bem aproveitados. É preciso conquistar o cliente, o público alvo e direcionar os esforços.

6. Rede de contatos: é importante participar de eventos e feiras relacionados ao seu produto. Lembre-se também de que ambientes informais ajudam a formar bons contatos.

7. Criar valor para a sociedade: o empreendedor deve fazer de seu negócio algo reconhecido pelos steakholders como um negócio útil para a sociedade.

8. Preparar-se para o crescimento do empreendimento: o empreendedor deve preparar-se para tomar as decisões do dia-a-dia do negócio alicerçadas num crescimento sustentável financeiramente e socialmente.

9. Ter critérios pessoais identificados com o negócio: os clientes cada vez mais percebem a postura da empresa em relação ao ambiente social, político, ambiental e financeiro. Ter atitudes condizentes com seu negócio é uma oportunidade de ir solidificando-o.

10. Liderança: O empreendedor deve ser o líder na sua empresa. Ele deve ser um bom ouvinte e deve saber estimular permanentemente a equipe, motivá-la e deixá-la comprometida. Liderar pelo exemplo é decisivo para o sucesso do empreendimento.

\section{Conclusão}

Para ser um empreendedor é preciso superar muitos desafios, pois transformar o sonho em realidade, ou seja, transformar projetos em ações concretas, é um caminho difícil de ser percorrido em função das barreiras que o empreendedor encontra ao longo da jornada. Disseminar uma educação empreendedora pode ser um caminho para ultrapassar as barreiras com mais conhecimento e competência.

É importante que o empreendedor se qualifique e consiga enfrentar as dificuldades, não só com vontade, mas com a convicção de que seu conhecimento o ajudará a atingir seu objetivo. Cada vez mais sociedade e empresas de todos os tamanhos percebem a importância e a necessidade da cultura empreendedora. Ações isoladas de empreendedorismo não se constituem em cultura empreendedora, porém a integração dessas práticas vai, ao longo do 
tempo, formando a cultura empreendedora. Essa cultura deve estar enraizada nos indivíduos que almejam serem empreendedores.

Desta forma, universidades, entidades de classe, autoridades devem perseguir a implementação de uma educação dirigida ao empreendedorismo, buscando cada vez mais o desenvolvimento do país. O fomento de uma maior cultura empreendedora, bem como a educação, torna os empreendedores mais capacitados a competir em um mercado que sofre continuamente mudanças cada vez mais rápidas em seu cenário.

Através do estudo realizado buscou-se esclarecer o desenvolvimento das qualidades e habilidades necessárias a um empreendedor inovador, como a capacidade de enxergar novas oportunidades, a iniciativa e a tomada de decisões e a confiança na elaboração de futuros projetos. Deve-se levar em consideração que o investimento em educação empreendedora implica em investir num potencial socioeconômico, já que o empreendedorismo é parte da solução para as dificuldades econômicas encontradas no país.

A educação empreendedora auxilia o estudante, desde os níveis iniciais de sua formação até a sua maturação profissional, a enxergar e avaliar determinadas situações, assumindo uma posição de eficiência frente a ela, capacitando-o nos planejamentos e nas formas e estratégias de interagir com aquilo que ele passou a perceber.

Desta forma, a educação empreendedora deve ter início ainda nas formações fundamentais de ensino, preparando os jovens não apenas para o concorrido mercado de trabalho, mas também para que sejam direcionados para atuarem como empreendedores. Devem ter a percepção de novas oportunidades e tentar minimizar as possíveis oscilações do mercado financeiro, reduzindo ao máximo seus riscos e contribuindo para a ascensão do nosso país para uma nova realidade econômica e social.

Por fim, as características compiladas neste estudo são capazes de nortear este processo da educação empreendedora, apresentando também como alternativa a busca de qualificação com o protagonismo e liderança responsáveis na formação do jovem para a sociedade do futuro.

\section{Referências}

AUdRETSCH, D. B.; BÖNTE, W.; TAMVADA, J. P. Religion, Social Class, and Entrepreneurial Choice. Journal of Business Venturing, v. 28, p. 774-789, 2013.

BARON, R. A.; SHANE, S. A. Empreendedorismo: uma visão do processo. São Paulo: Cengage Learning, 2013. 
BOLSON, E. L. A educação é o único caminho para criar uma sociedade mais empreendedora no Brasil. Disponível em: $<$ http://www.administradores.com.br/mobile/artigos/negocios/educacaoempreendedora/786/n dedora/786/>. Acesso em: 28 abr. 2017.

BORGES, C. Empreendedorismo sustentável / organização Candido Borges - 1. ed. - São Paulo: Saraiva, 2014.

CARVALHO, C.E.; ZUANAZZI, J. Análise das características de alunos de graduação em Administração e sua relação com as expectativas do ensino de empreendedorismo. In: EGEPE - Encontro de Estudos Sobre Empreendedorismo E Gestão De Pequenas Empresas. 3. 2003, Brasília. Anais... Brasília: 2003, p. 125-141.

DIAS, G. Dimensões Culturais: A Percepção de Dimensões da Cultura Brasileira a Partir de um Olhar. Tese (Mestrado em Administração) - Universidade Federal do Rio de Janeiro. Rio de Janeiro, 2012.

DOLABELA, F. O ensino do empreendedorismo: panorama brasileiro. Empreendedorismo: ciência, técnica e arte. Brasília: CNI - IEL Nacional, 2000.

DOLABELA, F. Oficina do Empreendedor. Rio de Janeiro: Sextante, 2008.

DOLABELA, F. Minha visão sobre empreendedorismo. Disponível em: $<$ https://fernandodolabela.wordpress.com/about/>. Acesso em: 22 mai. 2017.

DORNELAS, J. C. A. Empreendedorismo corporativo: como ser empreendedor, inovar e se diferenciar na sua empresa. 2. ed. Rio de Janeiro: Elsevier, 2008.

DORNELAS J. C. A. Empreendedorismo: transformando ideias em negócios. 6. ed. - Rio de Janeiro: Atlas, 2016.

DREHER, M. T. Empreendedorismo e responsabilidade ambiental: uma abordagem de empreendimentos turísticos. Tese (Doutorado em Engenharia da Produção) - Universidade Federal de Santa Catarina, Florianópolis, 2004.

DRUCKER, P. F. Inovação e espírito empreendedor: práticas e princípios. Edição revisada, São Paulo: Cengage Learning, 2017.

FILLION, L. J. Empreendedorismo: empreendedores e proprietários-gerentes de pequenos negócios. Revista de Administração, São Paulo, v.34, n.2, p.05-28, abril-junho 1999.

FUNDAÇÃO ANTONIO MENEGHETTI. Posicionamento Institucional. Aanis II Cong. Int. Uma Nova Pedagogia para a Sociedade Futura. Recanto Maestro: Fundação Antonio Meneghetti, $2016 . \quad$ Disponível em: $<$ http://reciprocidade.emnuvens.com.br/novapedagogia/article/view/132/153>. Acesso em: 30 out. 2018.

GEM. Global Entrepreneurship Monitor. GEM 2016. GEM America Latina y el Caribe 2015, v. 16, 2016. 
GIL, A. C. Como elaborar projetos de pesquisa. 4. ed. São Paulo: Atlas, 2008.

GREATTI, L.; PREVIDELLI, J.J. Ambiente cultural como elemento fundamental na formação do perfil empreendedor. In: Encontro De Estudos Sobre Empreendedorismo E Gestão De Pequenas Empresas, 3. 2003, Brasília. Anais... 2003, CD.

GREATTI, L. Perfis Empreendedores: Análise comparativa das trajetórias de sucesso e do fracasso empresarial no município de Maringá. 2005. Disponível em: www.facef.br/facefpesquisa/2005/nr1/6_greatti.pdf. Acessado em 10 de maio de 2017.

GUERRA, M. J.; GRAZZIOTIN, Z J. Educação empreendedora nas universidades brasileiras. In: Lopes, R.M.A. Educação empreendedora: conceitos, modelos e práticas. Rio de Janeiro: Elsevier; São Paulo: Sebrae.2010. p. 67-84.

KAWASAKI, G. El arte de empezar 2.0: la guia definitiva para empezar cualquier negocio del mundo 2.0 - 1. ed. - Ciudad Autónoma de Buenos Aires: Paidós, 2016.

LACERDA, D. P. Cultura organizacional: sinergias e alergias entre Hofstede e Trompenaars. Revista de Administração Pública. v.45, n.5, p. 1285-1301, 2011.

LAVIERI, C. Educação Empreendedora In: Lopes, R. M. A. (Org.). Educação empreendedora: conceitos, modelos e práticas. São Paulo: SEBRAE, 2010.

LIMA, E., NASSIF, V. M. J., LOPES, R. M. A., SILVA, D. Educação Superior em Empreendedorismo e Intenções Empreendedoras dos Estudantes - Relatório do Estudo GUESSS Brasil 2013-2014, 2015.

LOPES, R.M.A.; TEIXEIRA, M.A.A. Educação empreendedora no ensino fundamental. In: Lopes, R.M.A. (Org.). Educação empreendedora: conceitos, modelos e práticas. Rio de Janeiro: Elsevier: São Paulo: Sebrae, 2010.

MENEGHETTI, A. A pedagogia ontopsicológica. 3. ed. Recanto Maestro: Ontopsicológica Editora Universitária, 2014.

MENEGHETTI A. Pedagogia Contemporânea: Responsabilidade e Formação do Líder para a sociedade futura/ Fundação Antonio Meneghetti - Recanto Maestro: São João do Polêsine, RS: Fundação Antonio Meneghetti, 2017, p. 23-41.

NARDON, L; STEERS, R. M. The Culture Theory Jungle: divergence and convergence in models of national culture. Cambridge Handbook of Culture, Organizations, and Work, Cambridge: Cambridge University Press, 2009.

NOVAES, M.B.C.; GIL, A. C. A pesquisa-ação participante como estratégia metodológica para o estudo do empreendedorismo social em administração de empresas. RAM, Rev. Adm. Mackenzie (Online), São Paulo, vol. 10, n. 1, fev. 2009. Disponível em: $<$ http://www.scielo.br/scielo.php?script $=$ sci_arttext\&pid $=\mathrm{S} 1678$

69712008000500006\&lng=pt\&nrm=iso\&tlng=en>. Acesso em: 26 abr. 2017. 
OLIVEIRA, J. M.;PEREIRA, E.. P. C.; DORION, E. Uma Visão Pedagógica para o Ensino do Empreendedorismo dentro da Universidade. In: Congresso Internacional Lassalista de Educação, Canoas, 2003.

OLIVEIRA, J. M. Modelo para a integração dos mecanismos de fomento ao empreendedorismo no âmbito das universidades: o caso da Universidade Federal do Rio Grande do Sul. (Tese) Universidade Federal de Santa Catarina, Programa de Pós-Graduação em Engenharia de Produção, Florianópolis, 2006.

REZENDE, R. Empreendedor - Negócios Criativos, Inovadores e Rentáveis. Cultura Empreendedora Deve Começar na Sala de Aula. 2014. Disponível em: http://empreendedor.com.br/noticia/cultura-empreendedora-deve-comecar-nas-salas-de-aula/> Acesso em 12 de fevereiro de 2017.

RITCHIE, B.; BRINDLEY, C. Cultural determinants of competitiveness within SMEs. Journal of Small Business and Enterprise Development, Emerald Group Publishing, v. 12, n. 1, p. 104-119, 2005.

SAINI, J. S. Economic Development and Entrepreneurship. In: SAINI, J. S.; GURJAR, B. R. (eds.). Entrepreneurship and Education Challenges and Strategies. Jaipur: Rawat Publications. 2001.

SCHWARTZ, S. H. An Overview of the Schwartz Theory of Basic Values. The Hebrew University of Jerusalem, 2012.

SEBRAE. Programa Nacional de Educação Empreendedora. Disponível em: $<$ https://www.sebrae.com.br/sites/PortalSebrae/estudos_pesquisas/pesquisagemempreendedorismo-no-brasil-enomundodestaque9,5ed713074c0a3410VgnVCM1000003b74010aRCRD $>$ Acesso em: 22 mai. 2017.

STEVENSON, H. H.; GUMPERT, D. E. The heart of entrepreneurship. Harvard Business Review, v. 1, n. 63, p. 85-94, mar.-abr. 1985.

UNCTAD Secretariat (2015). "Division on Investment and Enterprise: Results and Impact - Report 2015," United Nations Conference on Trade and Development (UNCTAD), Genebra. http://unctad.org/en/PublicationsLibrary/ diae2015d1_en.pdf. Acesso em: 21 mai.2017.

ZHAO, F. Exploring the synergy between entrepreneurship and innovation. International Journal of Entrepreneurial Behaviour \& Research. Emerald Group Publishing Limited. Austrália, 2005, vol. 11, n. 1, p. 25-41. 